\title{
Preventive Effect of Flavangenol on Ischemia/Reperfusion-Induced Acute Renal Failure in Rats
}

\author{
Mamoru Ohkita, ${ }^{a}$ Atsushi NaKajima, ${ }^{a}$ Kyoko Ueda, ${ }^{a}$ Masanori Takaoka,${ }^{a}$ Yoshinobu Kiso, ${ }^{b}$ and \\ Yasuo MATSUMURA*,a \\ ${ }^{a}$ Department of Pharmacology, Osaka University of Pharmaceutical Sciences; 4-20-1 Nasahara, Takatsuki, Osaka \\ 569-1094, Japan: and ${ }^{b}$ Institute for Health Care Science, Suntory Ltd.; Shimamoto-cho, Mishima-gun, Osaka 618-8503, \\ Japan. Received April 19, 2005; accepted June 6, 2005; published online June 9, 2005
}

\begin{abstract}
The effects of flavangenol on ischemia/reperfusion-induced acute renal failure (ARF) in rats were examined. Ischemic ARF was induced by occlusion of the left renal artery and vein for $\mathbf{4 5} \mathrm{min}$ followed by reperfusion, 2 weeks after contralateral nephrectomy. Renal functional parameters such as blood urea nitrogen, plasma creatinine, creatinine clearance, urine flow, urinary osmolality and fractional excretion of sodium were measured. Renal function in ARF rats markedly decreased at $1 \mathrm{~d}$ after reperfusion. Pre-ischemic treatment with flavangenol $(3-30 \mathrm{mg} / \mathrm{kg}$, i.v.) attenuated the ischemia/reperfusion-induced renal dysfunction. Histopathological examination of the kidney of ARF rats revealed severe renal damage, such as tubular necrosis and proteinaceous casts in tubuli, which were also significantly suppressed by the administration of flavangenol. These findings suggest that flavangenol supplementation may be a promising candidate for treatments to improve the ischemia/reperfusioninduced renal injury.
\end{abstract}

Key words flavangenol; acute renal failure; ischemia; reperfusion

Flavangenol, an extract from French martima pine bark (PBE), is a complex mixture of bioflavonoids with oligomeric proanthocyanidin as main constituents. The nutritional supplementation of PBE produces a variety of potentially protective effects against chronic age-related diseases such as atherosclerosis, hypertension, and diabetes. It has recently been reported that many beneficial effects of PBE are closely related to its potent antioxidative and free radical scavenging function. ${ }^{1)}$

The post-ischemic renal injury occurs frequently in patients after major surgery, trauma, and transplantation. In general, ischemic acute renal failure (ARF) is induced not only by the ischemia itself but also by the following reperfusion. One of the pivotal causal factors in the post-ischemic renal injury is an enhancement of reactive oxygen species (ROS) production in renal and vascular tissues, although several factors such as ATP depletion and vasoactive peptides are complicatedly involved in the pathogenesis of this renal damage. ${ }^{2,3)}$ Thus, there is a possibility that administration of antioxidants prior to enhancement of ROS production may prevent the development of renal damage.

In the present study, we examined whether flavangenol treatment could overcome the ischemia/reperfusion-induced renal injury in rats.

\section{MATERIALS AND METHODS}

Materials Flavangenol was obtained from Suntory Ltd. (Osaka, Japan). All other reagents were commercial products of the highest grade available.

Animals and Experimental Design Male SpragueDawley rats (10 weeks of age, Japan SLC, Shizuoka, Japan) were used. Animals were housed in a light-controlled room with a $12 \mathrm{~h} \mathrm{light/dark} \mathrm{cycle} \mathrm{and} \mathrm{were} \mathrm{allowed} \mathrm{ad} \mathrm{libitum} \mathrm{ac-}$ cess to food and water. Experimental protocols and animal care methods in the experiments were approved by the Experimental Animal Committee at Osaka University of Pharmaceutical Sciences. Two weeks before study (at 8 weeks of age), the right kidney was removed through a small flank incision under pentobarbital anesthesia $(50 \mathrm{mg} / \mathrm{kg}$, i.p.). After a 2-week recovery period, these rats separated into five groups: (1) sham-operated control, (2) untreated ischemic ARF, (3) ischemic ARF pretreated with flavangenol (3 mg/ $/ \mathrm{kg}$, i.v.), (4) ischemic ARF pretreated with flavangenol $(10 \mathrm{mg} /$ $\mathrm{kg}$, i.v.), (5) ischemic ARF pretreated with flavangenol $(30 \mathrm{mg} / \mathrm{kg}$, i.v.). To induce ischemic ARF, rats were anesthetized with pentobarbital $(50 \mathrm{mg} / \mathrm{kg}$, i.p.), and the left kidney was exposed through a small flank incision. The left renal artery and vein were occluded with a nontraumatic clamp for $45 \mathrm{~min}$. At the end of the ischemic period, the clamp was released to allow reperfusion. Flavangenol or vehicle (a mixture of $2.5 \%$ ethyl alcohol, $30 \%$ polyethylene glycol 400, and $67.5 \%$ saline) in a volume of $1 \mathrm{ml} / \mathrm{kg}$ was injected $5 \mathrm{~min}$ before ischemia. In sham-operated control rats, the kidney was treated identically, except for the clamping. Animals exposed to 45-min ischemia were housed in metabolic cages $24 \mathrm{~h}$ after the ischemia. At the end of urine collection for $5 \mathrm{~h}$, blood samples were drawn from the thoracic aorta, and then the left kidneys were excised under pentobarbital anesthesia $(50 \mathrm{mg} / \mathrm{kg}$, i.p.). These urine and blood samples were used for measurement of renal function parameters as described previously. ${ }^{4)}$

Histological Studies Histological studies were performed as described previously. ${ }^{4)}$ Histopathological changes were graded as no damage (0), mild (1), moderate (2), severe (3), and very severe (4) based on the microscopical observations of each section.

Statistics Analysis All values are expressed as mean \pm S.E.M. Relevant data was processed by InStat (Graph-PAD Software for Science, San Diego, CA, U.S.A.). Statistical analysis of variance followed by Dunnett's tests for multiple comparisons. Histological data were analyzed using the Mann-Whitney test. For all comparisons, difference were considered significant at $p<0.05$. 


\section{RESULTS}

Renal Function after the Ischemia/Reperfusion and Effect of Flavangenol Treatment As shown Fig. 1, renal function of rats subjected to $45 \mathrm{~min}$ ischemia showed a marked deterioration when measured at $24 \mathrm{~h}$ after the reperfusion. As compared with sham-operated rats, untreated ARF rats showed significant increases in blood urea nitrogen (100.3 \pm 8.6 versus $28.9 \pm 1.8 \mathrm{mg} / \mathrm{dl})$, plasma creatinine concentration $(2.50 \pm 0.26$ versus $0.76 \pm 0.08 \mathrm{mg} / \mathrm{dl})$, urine flow $(88.5 \pm 7.8$ versus $24.0 \pm 1.6 \mu \mathrm{l} / \mathrm{min} / \mathrm{kg}$ ), and fractional excretion of sodium $(1.86 \pm 0.25$ versus $0.35 \pm 0.06 \%)$ and significant decreases in creatinine clearance $(1.34 \pm 0.29$ versus $4.18 \pm 0.37 \mathrm{ml} / \mathrm{min} / \mathrm{kg}$ ) and urinary osmolality (422 $\pm 43 \mathrm{ver}$ sus $1693 \pm 64 \mathrm{mOsm} / \mathrm{kg}$ ). Treatment of flavangenol dose-dependently attenuated the ischemic ARF-induced renal dysfunction. The administration of flavangenol $(30 \mathrm{mg} / \mathrm{kg})$ to sham-operated animals produced no effects in their renal functional parameters (data not shown).

Histological Renal Damage after the Ischemia/Reperfusion and Effects of Flavangenol Treatment Histopathological examination revealed sever lesions in the kidney of untreated ARF rats ( $24 \mathrm{~h}$ after the ischemia/reperfusion). These changes were characterized by tubular necrosis in the outer zone outer stripe of medulla (Fig. 2B; scores, $3.67 \pm 0.21$ ), medullary congestion and hemorrhage in the outer zone inner stripe of medulla (Fig. 2E; scores, 3.50土 0.34 ), and proteinaceous casts in tubuli in the inner zone of medulla (Fig. 2H; scores, 3.67 \pm 0.21 ). Treatment of flavangenol $(30 \mathrm{mg} / \mathrm{kg})$ significantly attenuated the develop-

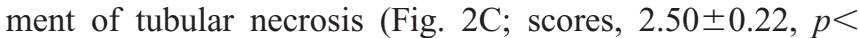
0.01 ) and proteinaceous casts in tubuli (Fig. 2I; scores, $2.17 \pm 0.40, p<0.01)$ except medullary congestion and hemorrhage (Fig. 2F; scores, 2.67 $\pm 0.33, p=0.0727$ ). On the other hand, no histopathological changes were observed in the kidney of sham operated animals (A, D, and G in Fig. 2).

\section{DISCUSSION}

In the present study, we obtained evidence that prior administration of flavangenol dose-dependently overcame the ischemia/reperfusion-induced renal dysfunction in rats. Histological examination of the post-ischemic kidney in untreated ARF rats revealed tissue injuries, such as proteinaceous casts in tubuli, and tubular necrosis, and these lesions were significantly suppressed by pre-ischemic treatment with flavangenol. These results indicate that flavangenol has preventing effects on the ischemia/reperfusion-induced renal dysfunction and degeneration.

Ischemic ARF is a frequent clinical syndrome with high morbidity and mortality. Reperfusion of previously ischemic renal tissue initiates a complex cellular events that results in injury and the eventual death of renal cells due to a combination of apoptosis and necrosis. ${ }^{5}$ The molecular mechanisms underlying the ischemia/reperfusion-induced renal injury remain unclear, but it has been reported that several causal factors (ATP depletion, phospholipase activation, neutrophil infiltration, vasoactive peptides etc.) are contributive to the pathogenesis of this renal damage. ${ }^{3)}$ Oxidative stress has also been considered as one of the factors which definitely involved in the development of the ischemic ARF. We and oth-

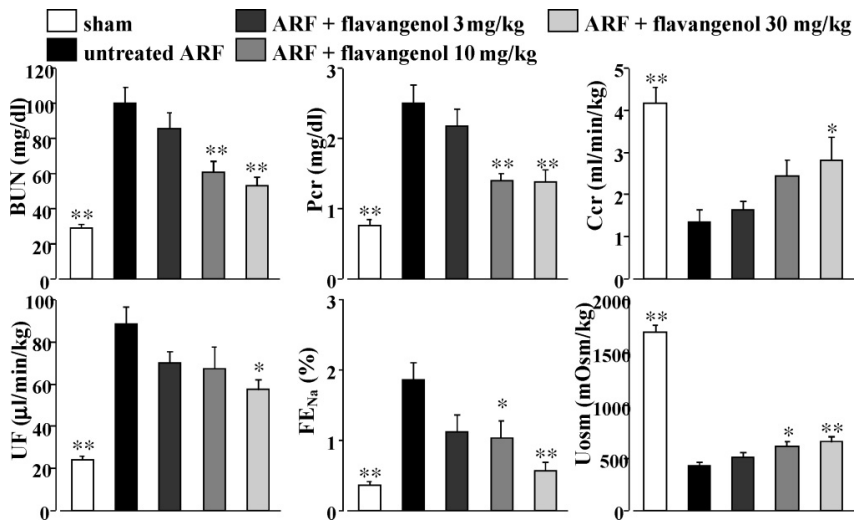

Fig. 1. Effects of Flavangenol on Renal Function $24 \mathrm{~h}$ after Ischemia/Reperfusion

Effects of flavangenol administered before ischemia $(3,10,30 \mathrm{mg} / \mathrm{kg}$, i.v.) on blood urea nitrogen (BUN), plasma creatinine concentration (Pcr), creatinine clearance (Ccr), urine flow (UF), fractional excretion of sodium $\left(\mathrm{Fe}_{\mathrm{Na}}\right)$, and urinary osmolality (Uosm) at $24 \mathrm{~h}$ after ischemia/reperfusion. Flavangenol was given $5 \mathrm{~min}$ before ishemia. Each column and bar represents the mean \pm S.E.M. $(n=6)$. $* p<0.05, * * p<0.01$, compared with untreated ARF rats; ARF: acute renal failure.
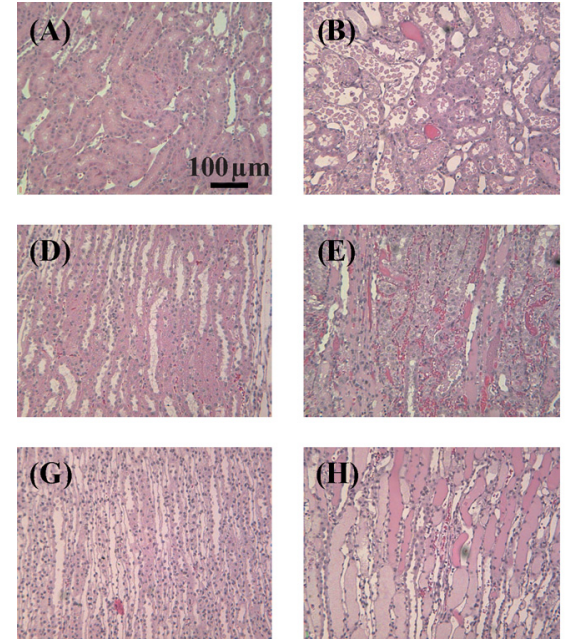
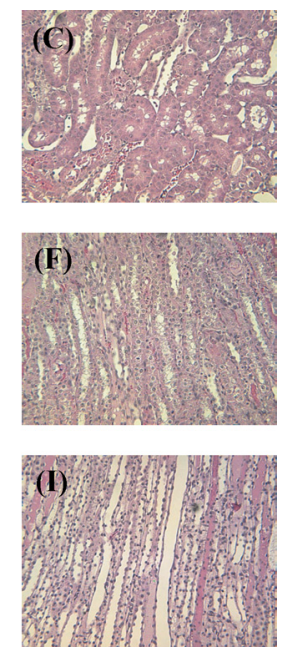

Fig. 2. Light Microscopy of Outer Zone Outer Stripe (A-C), Outer Zone Inner Stripe $(\mathrm{D}-\mathrm{F})$, and Inner Zone $(\mathrm{G}-\mathrm{I})$ of Medulla of the Kideny of ARF Rats Untreated (B, E, H) and Treated with Flavangenol $(30 \mathrm{mg} / \mathrm{kg}, \mathrm{C}$, $\mathrm{F}, \mathrm{I})$ at $24 \mathrm{~h}$ after Ischemia/Reperfusion, and Sham-Operated Rats (A, D, G)

Severe tubular necrosis (B), congestion and hemorrhage (E) and proteinaceous casts in tubuli $(\mathrm{H})$ are observed in untreated ARF rats; ARF: acute renal failure. Magnification $\times 200$.

ers have reported that several agents possessing an antioxidative activity ameliorate the ischemia/reperfusion-induced renal damage. ${ }^{6-8)}$ Kasuno et al. have also demonstrated that thioredoxin, a redox-regulating protein, play a protective role in the early phase of renal ischemia/reperfusion injury. ${ }^{9)}$ Pycnogenol (the similar extract from French martima pine bark as flavangenol) have been shown to possess excellent radical scavenger properties. It has been reported that, in addition to its radical scavenging activity, pycnogenol can stimulate intracellular defenses against free radicals by enhancing the production of antioxidative enzymes. ${ }^{1)}$ Moreover, there is accumulating evidence indicating that procyanidins, which are one of components of pycnogenol, have a potent antioxidative activity and improve ischemia/reperfusion-induced cardiac damage. ${ }^{10,11)}$ Taken together with these findings, it is reasonable to consider that the beneficial effect of fla- 
vangenol on the ischemia/reperfusion-induced renal damage is closely related to the antioxidative effects, although further studies are required to clarify how much antioxidative effects of flavangenol are involved in the improvement of renal damage and whether procyanidins mainly play an important role in flavangenol's action.

In many tissues, the ischemia/reperfusion induces a variety of gene expressions including adhesion molecules, cytokines, and vasoactive peptides. ${ }^{12,13)}$ It has been well known that a transcriptional factor nuclear factor-kappa $\mathrm{B}(\mathrm{NF}-\kappa \mathrm{B})$ is mainly responsible for the regulation of these gene expressions. ${ }^{14)}$ We and others have demonstrated that the suppression of NF- $\kappa \mathrm{B}$ could become a novel therapeutic strategy for ischemia/reperfusion-induced tissue damage. ${ }^{15,16)}$ There is accumulating evidence that pycnogenol has an inhibitory effect on NF- $\kappa \mathrm{B}$ activation in macrophages and vascular endothelial cells. ${ }^{17,18)}$ Most recently, we have found that flavangenol markedly suppresses tumor necrosis factor$\alpha$-induced NF- $\kappa \mathrm{B}$ activation in cultured vascular endothelial cells (Ohkita et al., unpublished observation). Thus, it is likely that inhibition of NF- $\kappa \mathrm{B}$ activation by flavangenol treatment is related, at least, to the amelioration of ischemia/ reperfusion-induced renal damage. Further studies are needed to clarify the detailed mechanisms underlying the beneficial effects of flavangenol against the ischemia/reperfusion-induced renal injury.

Acknowledgments This work was supported by a "High-Tech Research Center" Project for Private Universities: matching fund subsidy from MEXT (Ministry of Education, Culture, Sports, Science and Technology), 2002-2006.

\section{REFERENCES}

1) Rohdewald P., Int. J. Clin. Pharmacol. Ther, 40, 158-168 (2002).

2) Edelstein C. L., Ling H., Schrier R. W., Kidney Int., 51, 1341-1351 (1997).

3) Padanilam B. J., Am. J. Physiol. Renal. Physiol., 284, F608-F627 (2003).

4) Fujii T., Takaoka M., Tsuruoka N., Kiso Y., Tanaka T., Matsumura Y., Biol. Pharm. Bull., 28, 361-363 (2005).

5) Lieberthal W., Levine J. S., Am. J. Physiol., 271, F477-F488 (1996).

6) Fujii T., Takaoka M., Muraoka T., Kurata H., Tsuruoka N., Ono H., Kiso Y., Tanaka T., Matsumura Y., Eur. J. Pharmacol., 474, 261-267 (2003).

7) Takaoka M., Ohkita M., Kobayashi T., Yuba M., Matusmura Y., Clin. Exp. Pharmacol. Physiol., 29, 189-194 (2002).

8) Doi K., Suzuki Y., Nakao A., Fujita T., Noiri E., Kidney Int., 65, $1714-1723$ (2004).

9) Kasuno K., Nakamura H., Ono T., Muso E., Yodoi J., Kidney Int., 64, 1273-1282 (2003).

10) Maffei Facino R., Carini M., Aldini G., Berti F., Rossoni G., Bombardelli E., Morazzoni P., Planta Med., 62, 495-502 (1996).

11) Maffei Facino R., Carini M., Aldini G., Berti F., Rossoni G., Bombardelli E., Morazzoni P., Life Sci., 64, 627-642 (1999).

12) Lipton P., Physiol. Rev., 79, 1431-1568 (1999).

13) Devarajan P., Mishra J., Supavekin S., Patterson L.T., Steven Potter S., Mol. Genet. Metab., 80, 365-376 (2003).

14) Richmond A., Nat. Rev. Immunol., 2, 664-674 (2002).

15) Takaoka M., Matsumura Y., Recent Res. Devel. Life Sci., 1, 203-220 (2003).

16) Azuma H., Tomita N., Kaneda Y., Koike H., Ogihara T., Katsuoka Y., Morishita R., Gene Ther, 10, 415-425 (2003).

17) Peng Q., Wei Z., Lau B. H., Cell Mol. Life Sci., 57, 834-841 (2000).

18) Cho K. J., Yun C. H., Yoon D. Y., Cho Y. S., Rimbach G., Packer L., Chung A. S., Toxicol. Appl. Pharmacol., 168, 64-71 (2000). 